\title{
A critical examination of the interaction of crisis leadership \& corporate reputation
}

\author{
Evangelia Fragouli \\ School of Business, University of Dundee, UK
}

\section{Keywords}

Crisis, leadership, corporate reputation, stakeholders

\begin{abstract}
Effective leadership in dealing with a crisis is of critical importance since crisis situations often put companies or organizations at high risks threatening their reputation, stability $\mathcal{E}$ survival. Considering that a crisis can present itself in a number of different ways, as well as there are multiple factors that affect individual leadership styles. a leader must be able to distinguish between these ways and adapt the right style and behaviours accordingly. This paper, through a critical literature review methodology, explores 'how' leadership underpins corporate reputation in a crisis situation reviewing also the key factors influencing leadership effectiveness in such stressful situations. The study concludes that the leadership role is important in supporting the corporate reputation in a crisis situation and suggests that practitioners must comprehend different dimensions of crisis that affect leadership styles, allowing for effective management of the situation. Additionally, the study emphasizes that different preparations, precautions, and adaptations must be considered before choosing a leadership style to effectively navigate the organisation through crisis. The study confirms that a good reputation helps corporations to gain the trust of consumers and reduce the losses caused by the crisis, as well as, corporations in crisis should choose appropriate leadership style so that leaders to create a culture that could predict threats and risks.
\end{abstract}

\section{Introduction}

Corporate reputation refers to the degree to which an enterprise is trusted and praised by the public, as well as the degree to which the enterprise affects the public (Barnett, Jermier and Lafferty, 2006). The development of media facilitates the value of each enterprise to become known by the public (Aula, 2010). With a high degree of transparent oversight, corporate reputation management glitches are more likely to be amplified (Dijkmans, Kerkhof and Beukeboom, 2015). Once the reputation of the enterprise is lost, it means that the crisis of the enterprise is triggered. Cravens, Goad Oliver and Ramamoorti (2003) claimed that better leadership can change people's perception of the negative image of the organization. When an enterprise is in crisis, a strong leadership can help the enterprise gradually recover the lost reputation and regain the trust of stakeholders (Jin and Yeo, 2011). Therefore, leadership is about leaders building bridges between the company and society through their own efforts (Ilies, Morgeson and Nahrgang, 2005). Under the influence of excellent leadership, leaders can encourage employees to achieve organizational goals, make enterprises pay attention to reputation risk, and motivate the whole organization to protect company's reputation in the case of crisis (Avolio and Gardner, 2005).

Fombrun (2012) introduced that corporate reputation is a collective assessment of a company's attractiveness to a specific group of stakeholders as opposed to a reference group of companies with which the company competes for resources. Corporate reputation is a vital intangible asset as well as a significant long-term strategic goal of a company (Dowling, 1993). Roberts \& Dowling (2002) believe that high reputation can bring huge profits to the company. In addition, these profits together with the company's potential value will continue to grow over time. In general, high reputation contributes to the company from the following aspects: 1) optimizing shareholder value, 2) attracting customers and highquality employees, 3) increasing businesses during the upswings of the market, and 4) protecting businesses during the economic recession. Therefore, high corporate reputation becomes particularly crucial to the survival and development of a company. Patrick, Adeosun and Ganiyu (2013) pointed out that corporate reputation is an intangible strategic asset of a company. Companies are usually seeking effective reputational risk management (RRM) methods for management aiming to protect and enhance corporate reputation (Burke, 2003). Unerman (2008) points out that good performance of corporate social 
responsibility can effectively reduce reputational risk. Mahon (2002) believes that a good corporate reputation and reputation risk management are competitive advantages, a good corporate reputation will make suppliers and partners more willing to strengthen cooperation with the enterprise.

\section{A brief examination of factors affecting corporate reputation}

Factors which influence corporate reputation include leadership and stakeholders (Stavrinoudis and Chrysanthopoulou, 2017; Moleleki, 2011; Matuleviciene and Stravinskiene, 2015). Among them, leadership, as a significant factor affecting corporate reputation, is reflected in the annual survey of most corporate reputation measurement tools (such as AMAC of reputation merchants and wealth companies), which highlights the importance of leadership (Fombrun, Gardberg and Sever, 2000). Senior managers and employees are the most important factors that determine strategic decisions and organizational results. They decide to promote or defend their corporate reputation and act as the defender and supporter of corporate reputation (Helm, 2011). And in many cases, a leader's effectiveness seems to be synonymous with reputation, rather than any objective measure. Maintaining and developing a company's reputation is a leader's primary concern (Stavrinoudis and Chrysanthopoulou, 2017). Some of the world's most famous companies have high-profile, acclaimed leaders; In contrast, in recent years, other companies have also fallen into difficulties due to a leader's mismanagement during the crisis (Knight, 2017). Stakeholders are also important. Firms that are appreciated by stakeholders can gain a higher corporate reputation. And the larger stakeholders identify with the brand and the estimated firm leads to a higher corporate reputation. Because stakeholders can directly affect a company's image, reputation, and revenue through decisions, boycotts, mild retaliation, income taxes, and resource constraints. Therefore, stakeholders can indirectly influence corporate reputation through the relationship between stakeholders and enterprises. Stakeholders unconsciously form corporate reputations to a certain extent (Matuleviciene and Stravinskiene, 2015).Finally, if companies ignore the legislative changes related to the environment, they may damage their reputation and lose business, and there are many other legislative drivers that may damage the company's image (Moleleki, 2011).

\subsection{Compliance with the law and corporate reputation}

Compliance with the law is the foundation of the company's ethical behavior. If a company wants to establish a good corporate reputation, it must comply with laws and regulations, including international rules and contracts, laws and regulations and regulatory requirements in the country where the company is headquartered and where it operates. Enterprises should integrate compliance with laws and regulations into their corporate culture. When corporate culture emphasizes integrity and integrity, and the board of directors and senior management set an example, legal and reasonable operations can be effectively implemented. Enterprises should examine whether they have established a good legal management culture and a suitable environment to make full preparations for the implementation of legal management. An enterprise's compliance with laws and regulations can not only effectively reduce the risk of violations, but also in the long run, it will help improve the reputation of the company and reduce the negative reports of the news media to gain consumer trust. The purpose of a corporation is to maximize its shareholders ' returns and to ensure that compliance with the laws of the jurisdictions in which it operates constitutes socially responsible conduct. (Friedman, 1970)

\subsection{Stakeholders \& Corporate Reputation}

Corporate reputation is affected by many factors, among which stakeholders are important factors affecting corporate reputation, and leaders need to consider the needs of different stakeholders in order to have a better corporate reputation. Effective communication between leaders and stakeholders contribute to the management of corporate reputation (Helm, 2007). Social public satisfaction affects corporate reputation. Companies with high stakeholder satisfaction usually achieve higher corporate social performance (Neville, Bell and Mengüç, 2005). Timberland brand pays attention to customer satisfaction. Each product comes with a notification of customers' impact on the environment and the community. It gives consumers sufficient right to know and make decisions, which enhances the influence of the Timberland brand and ultimately makes Timberland shoes deeply affected. Volkswagen's favorite, and thus higher profits (Gillentine, 2006). Improving corporate employee welfare will enhance corporate reputation, which will allow the company to have good financial performance (Contini et al., 2019). In 
recent years, Huawei the company's market share has steadily increased, which is closely related to Huawei's strategy of adopting high employee benefits and sharing sufficient revenue for employees. Reasonable measures have made Huawei have a better corporate reputation. As a result, Huawei employees are willing to work longer independently and are full of passion while working, which ultimately brings good earnings performance to the company (Zhu et al., 2013). When a major crisis comes, stakeholders will have greater tolerance and tolerance for the company, which also provides companies with time to prepare for the crisis.

\subsection{Corporate Social Responsibility \& Corporate Reputation}

Corporate social responsibility means that enterprises need to take responsibility for improving society, environment, and operation (Moir, 2001). And corporate social responsibility has a positive effect on corporate reputation (Schnietz and Epstein, 2005). When an enterprise's reputation is in crisis, the good corporate social responsibility maintained by the enterprise can play a positive role in the repair process (Adams, 2008). So, in the wake of the Volkswagen scandal, the leadership has maintained its previous strategy of sustainable development and green energy (Horn et al., 2015). When an enterprise has strong leadership, it can not only help the enterprise to tide over the difficulties, but also prevent another major crisis (Zhu, Sun, and Leung, 2013).

Corporate social responsibility activities for customers to buy what kind of product or service plays a very important role (Šontaitè - Petkevičien è, 2015). According to Castaldo et al. (2009), some reports indicate that customers are affected by the organization's CSR activities. In addition, Park, Lee, and Kim (2014) argue that ethical and philanthropic CSR practices may create and cultivate clients' beliefs that organizations adhere to high ethical standards and care about the well-being of society. Therefore, Lamberti and Lettieri (2009) believe that if customers realize the moral meaning of organizational behavior, they will ensure that the organization will follow certain quality standards and maintain or improve its corporate reputation. Corporate social responsibility has become one of the significant factors that affect corporate reputation. Corporate social responsibility has become the top managers in the enterprise reputation building one of the most important business case ( $\breve{S}$ ontaitè - Petkevičien è, 2015).When corporate executives generally have high ethical leadership, corporate reputation will also be correspondingly improved with the improvement of CSR, so that companies will have a stronger ability to resist crisis. Groves and LaRocca (2011) pointed out that transactional leadership and transformational leadership often have different ethical values, which will lead to different CSR measures for companies. Hsu (2012) proposed that corporate social responsibility is increasingly important for companies in today's society. Hall et al (2015) pointed out that when a company with close social relations does not implement an appropriate corporate social responsibility strategy, the company's reputation will be affected, which will cause the company to fall into crisis. In 2009, two employees of the domino brand posted a video of the company preparing a pizza in an unsanitary manner on YouTube. This is a crisis caused by the company's failure to perform a good CSR, and the Domino Company only responded to this situation two days later. In response, consumers' perceptions of the Domino brand at this time were already very poor. This is a crisis caused by the company's failure to perform a good CSR, and Domino responded to this situation two days later, at this time consumers have a very bad impression of the Domino brand. This puts the company in a huge crisis (Young and Flowers, 2012). In addition, Schnietz and Epstein (2005) pointed out that companies that actively undertake CSR will be less affected in times of crisis. A company with a higher CSR reputation has a stronger ability to resist the crisis (Lins et al., 2017). This means that if a company handles the crisis from the perspective of a stakeholder, then the company with a higher CSR Companies can profit in a crisis. The case of Johnson \& Johnson's Tylenol is a good example. In 1982, someone died of taking a drug from Johnson \& Johnson. Johnson \& Johnson did not conceal information about 100,000 parts of the drug containing toxic substances, notified consumers across the country and recalled all medicine. After half a year, the company reoccupied most of the market for this medicine, and built a better corporate reputation, and later achieved better profit performance (Benson, 1988). In general, corporate CSR commitment is conducive to enhancing corporate reputation and has important value for corporate reputation in crisis (Schnietz and Epstein, 2005). 


\section{Leadership \& Crisis Management}

Every organisation aims to have a sustainable leadership system to best equip them to cope with crisis situations; crisis events are characterised by their unexpected and harmful nature. To be effective, leaders must prepare response strategies in an organised manner to remedy the issue as quickly and efficiently as possible (Bundy, et al., 2017). There are three main stages involved in leading in crisis: crisis prevention, crisis management and post crisis evaluation (Bundy, et al., 2017): Organisations view crisis from two distinct perspectives: internally, focussing on the internal dynamics of the organisation to manage the threat, complexity and technology required in crisis, and externally, considering the external environment and stakeholders and their impact and considerations in difficult periods (Bundy, et al., 2017). There are however distinguished commonalities between these perspectives that enable leaders to synthesise both into one single perspective, allowing them to approach the issue as one whole matter. For instance, leaders can identify constraints, such as internal social and behavioural concerns, that may hinder their relationship with external stakeholders (Bundy, et al., 2017). No organisation is always truly prepared for crisis; however, some do have a unique capability to soften the blow through training and preparation. Businesses should look to have dedicated training explaining to subordinates what to expect during crisis and what methods and actions are likely to be required to deal with it (Glodziński \& Marciniak, 2016). Publicly available specification for leaders during crisis (PAS: 200:2011) describes a structure highlighting four key demands of effectiveness that can be adopted by organisations in crisis management (Hamidovic, 2012): - Psychological demand, which involves the capability of inspecting situations, defining strategies, regulating choices, forming opinions and classifying their impacts, • Organisational demand, which consider the structures and methods required to convert decisions into reality and inspect their effects, - Cultural demand, which involves the inner capability of employees to share decisions and assist their superiors in taking action and realising goals, $\bullet$ Logistical demand, which involves the capability of making the correct decision at the right time.

\subsection{Leadership Styles Before Crisis}

Schnietz et al (2005) claim that companies with a high corporate reputation have stronger ability to resist crisis, enterprises will suffer less losses in the crisis, and their leaders' decisions in the crisis will be more easily accepted by the public. Leader's power is the key to a company's crisis resolution while leadership is abstract and uncontrolled. The effectiveness of crisis management and corporate reputation depend on strong leadership. Therefore, the strength of leadership directly affects the success or failure of a company in a crisis. Many scholars analyse leadership styles in three different stages of crisis: before, during and after. Crisis leadership is significant as there are many factors affecting it, including irregularity of situations and cost entailed (Prewitt, et al., 2011). Irresponsible crisis leadership can put the organisation at risk; in order to avoid this, leaders must analyse the implications of different styles and comprehend crisis theory so that they can anticipate unexpected situations whenever they may arise in the future (Prewitt, et al., 2011).

Generally, there is a lifecycle for any crisis, with each point requiring different strategies in order to lead the organisation to survival; a crisis lifecycle begins with a preparation phase, requiring training, information absorption, external environment forecasting and a deep understanding of all anticipated threats to minimise the risk and impact of unforeseen circumstances (Prewitt, et al., 2011). An understanding can be gained through a number of different ways: leaders can determine how prepared the organisation is to respond to the crisis, and what precautions can be taken, as well as what styles to adopt to best coach subordinates through the period of difficulty (Ucelli, 2002). Furthermore, communication can be made clearer by designing strategic programmes and implementing suitable communication protocols before crisis (Ucelli, 2002). The emergency phase, where the crisis occurs, requires timely and specific implementation of theories, tools and strategies learned in the preparation phase, while the final phase (adaptive steady-state) includes a revision of what has been accomplished during the crisis, what losses have been incurred and lessons that must be understood before a new crisis lifecycle takes over. (Fener \& Cevik, 2015).

Crisis management describes how leaders plan for crisis, and the key aims are listed (Cener, 2007, as cited in Fener \& Cevik, 2015): 1) To recognise major crisis events that may affect decision making, and provide information about the crisis process, 2) To allow leaders to identify crisis, and assess its impacts, 
3) To establish methods for dealing with and navigating out of crisis, 4) To provide leaders with skills for leading in crisis. In pre-crisis management, leaders analyse potential warning signs in an attempt to avert the crisis, and in some cases look to use the situation to their advantage (Fener \& Cevik, 2015). Leaders and organisations who account for crisis in their business strategy will have well versed routines to best cope, which their subordinates will be familiar with through regular training, while certain rooms and storage areas will have equipment ready to deal with unforeseen circumstances (Tafra-Vlahovic, 2013). Furthermore, extensive preparation coupled with high initiative and strong internal motivation within organisations can help to prevent crisis and related effects (Yukl, 1994, p. 451).

\subsection{Leadership Styles During Crisis}

There are multiple lenses through which leadership styles in crisis can be analysed. Crisis can occur for a number of reasons but can begin to manifest itself in an organisation through poor leadership and decision making, such as selling a core part of the business to other companies as they lack resources, time or expertise and are acting impulsively. Consequently, the ability of a leader to react effectively or impose a proper leadership style may be limited (Probst \& Raisch, 2005).To effectively deal with crisis, leaders must first recognise signs early, allowing them to understand the situation and formulate a plan of attack (Boin, et al., 2013). Leaders are then responsible for collating available information and quickly making a decision before effectively communicating this to subordinates (Boin, et al., 2013). Communication is imperative throughout, ensuring plans are executed to the highest possible standard, minimising disruption experienced within the organisation (Boin, et al., 2013). Furthermore, in situations where power is shared between more than one leader, communication is key to ensure everyone is moving in the same direction. It is often difficult for leaders to maintain concrete styles in this instance, however Probst \& Raisch, (2005), argue that adopting an autocratic leadership style can limit the impact of crisis on the organisation. Small changes where leaders can adapt their style to be innovative and allow for smooth transition between phases in crisis can navigate an organisation out of crisis (Probst \& Raisch, 2005).

During crisis, it is imperative that leaders remain composed and can operate effectively under pressure (Yukl, 1994, p. 264). This composure allows them to make considered, rational decisions on how best to lead the organisation so as not to aggravate the crisis situation they are in (Fener \& Cevik, 2015). Additionally, they can determine the nature of problems and their causes and take decisive corrective action (Yukl, 1994, p. 80), before clear improvement can be observed (Yukl, 1994, p. 384). Effective leaders have the confidence to take responsibility for their decisions and keep subordinates informed (Yukl, 1994, pp. 99, 101, 448), making their role in recovery clear (Yukl, 1994, p. 296). Adaptation of leadership styles relies on one fundamental approach that drives and controls other styles accordingly: charismatic leadership (Hasan \& Rjoub, 2017). During crisis, followers are coached and directed by leaders who have clear vision and communication, and charismatic leaders are more likely to convey messages and instructions in a way subordinates trust and adhere to (Hasan \& Rjoub, 2017). Leaders with good charisma have particular behaviours embedded in their personality, not evident in everyone (Jansen, et al., 2009): 1) They can impose an attractive strategy and vision that creates trust among followers, 2)They have the ability to perform unconventional practices in critical times, 3) They have great self confidence that allows them to take risks and responsibility and inspire others. Employees can be further motivated in crisis if the leader is passionate and concentrates on subordinate's success with a positive energy; if they have integrity and are equipped for any situation; and if they are prepared to contribute and lead through experience and expertise, rather than abusing their position of authority (Jansen, et al., 2009).Some leaders express different emotions that may affect their leadership style in crisis; they may become overwhelmed with fear, anger or sadness. The ability of a leader to control their emotions in responding to crisis is vital, as this can influence subordinate reaction as the brain responds to sender emotions and reacts accordingly (Madera \& Smith, 2009).

Leaders may choose to consult experts from outside the company as they can be too emotionally involved in the situation, prolonging the decision-making process, but ensuring a reasonable, unbiased course of action is chosen. If a crisis situation requires immediate response based on sustainable growth, the leader must be able to switch between leadership styles, such as autocratic, participative and charismatic depending on the nature of crisis and their own cognitive ability (Probst \& Raisch, 2005). Leaders must ensure that they adopt a leadership style in crisis that does not worsen the situation: not 
having sufficient resources or knowledge, ignoring potential threats, and making knee-jerk decisions can deepen crisis (Boin, et al., 2013). If an organisation is well balanced in its corporate governance in terms of growth, speed of change, leadership, and culture, leaders will be better placed to choose a suitable leadership style in crisis, recognising warning signs early on in the process, allowing for quicker adaptation and response to the situation (Probst \& Raisch, 2005). Hannah, et al., (2009) argue that different leadership styles can have different effects on leaders and followers depending on their relationship and how they are physically separated within the business. For example, if a leader shares the same level of risk and responsibility with subordinates, as seen in military conditions, they will be able to influence the dynamics of the crisis situation, and use follower's behaviour as an advantage, rather than an obstacle (Hannah, et al., 2009). Another factor that determines leadership style is the location and magnitude of the crisis. Large-scale, immediate danger requires instant, decisive action and the leader does not necessarily have time to analyse different possible strategies, while the location impacts who may be involved and other cost implications to the organisation (Hannah, et al., 2009).

\subsubsection{Factors and Demands Affecting Leadership Styles}

Adapting particular leadership styles depends on many factors including (Olafason, 2014): Establishing a strong, empathetic relationship with followers, as followers will tend to express their feelings and respond to orders if the leader has the ability to listen to and establish a connection with them; Having high levels of self-awareness, which will allow the leader to adapt quickly and respond effectively to crisis, as well as allowing them to establish limitations within individual plans ; Expressing plans and visions to subordinates through storytelling allows colleagues to fully understand and become more engaged in their work; Building trust with followers' aids leader credibility when acting in crisis as subordinates are less likely to question integrity, intent, capabilities and results

Each of these factors controls the ability of the leader to choose and implement a proper leadership style (Olafason, 2014). Communication and confidence are integral qualities leading in crisis. Should a leader not display these characteristics, they will not be able to reasonably make decisions or delegate tasks under time constraints, or relay information in teambuilding when their business needs reorganising (Van Wart \& Kapucu, 2011).

\subsection{Leadership Styles After Crisis}

Following crisis, managers and leaders must adapt their styles to conform to the new state of the organisation. They must find reasonable solutions to the impacts of the crisis and implement changes and new strategies to improve the standing of the organisation (Fener \& Cevik, 2015). Crisis situations can also be a learning curve for leaders, as their experience and knowledge grow from managing the case; their understanding of the crisis and why it occurred can be used to ensure they do not find themselves in a similar state again (Boin, et al., 2013; James \& Wooten, 2011). Following the fast-paced, frantic operations during crisis, it is normal for leaders to allow intensity to drop and to revert back to old habits that they are comfortable with. Ashkenas, (2012), argues that to follow a successful and sustainable business model capable of averting crisis situations, it is necessary for leaders and their colleagues to continue to work efficiently with high energy, even in non-crisis situations.

\subsubsection{Leadership Style \& Corporate Crisis Response}

Each leader has a unique leadership style. Different leadership styles can cope with different corporate crises. The right leader can help the company survive the crisis smoothly; otherwise it will bring disastrous consequences for the company. Bowers, Hall and Srinivasan (2017) pointed out that when a company encounters a crisis, it should first analyse the crisis itself, so as to select leaders that match the attributes of the crisis to resolve the current crisis according to the leadership traits. Indicative leadership is the most common leadership of today's enterprises. Indicative leaders have a strong self-confidence in themselves. Jordan-Meier (2012) believes that transactional leadership in US companies after World War II is very common that leaders meet employees' expectations through incentives and punishment. Wofford and Goodwin (1994) pointed out that under this leadership; leaders do not expect to change the existing state. This means that transactional leaders want companies' tasks can be completed according to the systematic and structured model of the enterprise. Because leaders are affected by the corporate system, such leaders will be at a loss for emerging new crises. (Trainor and Velotti, 2013). Transactional leadership 
is considered by many scholars as a leadership strategy that is good for business development. Yukl (1999) pointed out that transformational leadership guide the change of subordinates through incentives and improve their work performance by stimulating the self-efficacy of the subordinates. Bowers, Hall, and Srinivasan (2017) pointed out that during a crisis, transformational leaders tend to listen to the opinions of subordinates to reach consensus.

3.3.2 The role of Emotional \& Ethical Factors on Leadership.

The complexity of business management makes leaders often work under high pressure and need to respond quickly to tasks when information is scarce (Collins and Jackson, 2015). Different emotions generated under high pressure will affect the efficiency of decision-making. Madera and Smith (2009) points out emotional factors can have a certain effect on leadership. Negative emotional factors such as anger, frustration, and destructive leadership can lead to disruptive leadership (Krasikova Green and Lebreton, 2013). Such leaders are prone to harm decisions on corporate reputation. (Spreier, Fontaine and Malloy, 2006). However, not all emotions have a negative impact on leadership. Positive emotions of leaders such as enthusiasm and activities can have a positive effect on leadership. According to research by Sy, Côté and Saavedra (2005), Leader's positive attitude has a positive impact on follower performance and motivates followers. In addition, a transformational leadership are more likely to have a positive influence of emotions and feelings of followers (Footy et al, 2010). Therefore, emotional factors not only affect the generation of leadership, but also affect the moral quality of leaders. The impact of ethical factors on leadership is huge. Today's companies face many unknown risks. Any decision made by corporate managers may affect the reputation of the company. Messick and Bazerman (1996) proposed that decisions without ethical considerations can easily lead to companies' damage to reputation. The 2015 Volkswagen emissions scandal is a good proof of this fact (Siano et al., 2017). In order to increase sales, corporate leadership fraudulently claims that the new system can reduce carbon emissions. Emissions will eventually lead to damage to corporate reputation and company profits. Therefore, when making decisions, corporate managers not only need to consider accurate world system theories, but also need to consider ethical factors in decision making. In addition, corporate culture is subject to ethical leadership Influences increase corporate social responsibility (Too and Ofori, 2009) .This is because managers with ethical leadership influence the ethical behaviour of their subordinates and increase employee dedication (Mayer, Kuenzi and Greenbaum, 2010). This ethical factor will have different effects on different styles of leadership. Among them, transactional leadership is least affected.

\section{Effective Crisis Leadership \& Challenges}

Obydiennova (2019) pointed out that the crisis is unknown and sudden, so companies should use existing resources, allocate appropriate leadership, and implement effective measures to deal with the crisis, thereby reducing the reputation and assets of the company in the crisis. Yukl (2006) pointed out that when a company encounters a crisis, it should choose the appropriate leadership to deal with the current crisis according to the type of crisis at different stages (Burgess et al 1992)Leaders who can effectively deal with threats can make team members more engaged in work and reduce followers' ability to question decisions. In contrast, current leaders are inconsistent with the leadership style required by the current corporate crisis. It often leads to a crisis out of control. The result is devastating for businesses (Bowers, Hall, \& Srinivasan, 2017). Therefore, a more detailed analysis of the advantages and disadvantages of different leadership and the factors affecting leadership is required. Bruce and Luthans (2009) pointed out that according to leadership-related traits, leadership can be divided into transactional, transformational, and mentoring. According to the study of different leadership by Bath (2008), transactional leaders can better clarify decision-making goals for followers in the face of stress and corporate crises, while transformative leaders inspire followers by caring about employees. In order to make full use of corporate resources in the event of a corporate crisis, Rajah, Song and Arvey (2011) also studied the factors affecting leadership. They found that emotions have many effects on leadership, and they also affect their Followers have different influences. In addition to emotional factors, Zhu et al (2011) found that moral factors are also the main factors affecting leadership; Morality not only affects guiding power, but also affects the morals and price of followers. In addition, the effectiveness of crisis management as a leader's response to corporate crises is directly affected by leadership (Melissa, 2017).According to the research by 
Maldonado and Dusya (2014) effective crisis management can help companies protect their reputation during crises. At the same time, corporate reputation is also affected by CSR. Hall et al (2015) pointed out that companies need to implement appropriate corporate social responsibility strategies; otherwise their reputation will be affected. According to the research of Tom (2018), the corporate image in the mind of stakeholders also affects the reputation of the company, and companies which focus on stakeholders usually get better corporate reputation.

Another challenge for effective leadership is the context and nature of a crisis. Feam-Banks (1996) defines a crisis as a major event that happens with a potentially negative outcome and affects both an organization and its stakeholders. The Chinese character for "crisis" is a combination of the two characters "danger" and "opportunity". Coincidently, Brumfield (2012) believes that crisis is not necessarily a negative experience for all organizations. With proper planning and preparation, as well as the in-advance identification of potential problems, companies can take advantage of the crisis to gain benefits. Nevertheless, which of the "danger" and "opportunity" dominates often depends on the attitude of the leader. For this reason, Jaques (2012) highlights crisis leadership to be an important component of crisis management academics. Schoenberg (2005) also describes crisis leadership as one of the most important but least studied factors in crisis management. Furthermore, Davies and Chun (2009) point out that leaders play a central role in reputation management of a company. Leaders can personify the company into various stakeholders. The personalities of leaders have an influence on the corporate culture. In case of a crisis, internal and external stakeholders may insist that leaders assume important roles. For example, leaders' responses to crises may be closely correlated with company reputation (Cohen, 2004). FIFA's failure to restore its reputation in time for bribery elections is a typical example. Microsoft's reputation among consumers has gradually increased after the timely replacement of leaders. Therefore, only principle-based organizations with effective leadership and preparation can help a company survive from the crisis and even stand up from the storm. A crisis is an unstable time or state of affairs \& any business leader who can foresee and plan the turning point of the company is more likely to take advantage of this opportunity (Heller and Darling, 2012). Effective crisis management is conducive to promoting competition for enterprises. Ineffective crisis response can lead to competitive disadvantage and even endanger the survival of the enterprise. However, some leaders who are perceived as far-sighted, strategic, and disciplined have muddled through crises, often at great risk to their careers and the future of their companies. Leaders who mishandle the early stages of a crisis often act in such ways preventing the company from using resources early enough to control its own destiny. The four common mistakes leaders make are: 1) Ignore the problem: management doesn't seem to be aware of the real crisis; 2) Provide misleading information: management provides misleading statements of truth, thereby prompting an opponent or whistle-blower to reveal the whole story; 3 ). Claim situations against the reality: often the management deliberately lies in order to deceive; 4). Shift the blame to others: often the management tries to shift the focus from itself to others instead of taking meaningful steps to solve the problem (Fred Garcia, 2006).

\section{What is required to take place?}

\subsection{Leadership Needs to Face Challenges in Crisis}

Usually, crises are sudden and unpredictable. Therefore, leaders in a crisis face various challenges. Meriwether, Gordon (2018) believes that leadership needs in crisis are quite different from those in normal situations. Leaders in crisis usually need to face the following problems: First, in a corporate crisis, the decisions made by leaders may be insufficiently comprehensive due to internal and external pressures, resulting in unpredictable consequences. Second, time pressure is also the main factor influencing leadership. Leaders need to control the corporate crisis within the shortest period of time. This not only requires the leader to have the ability to respond to the crisis quickly, but also the leader to have the ability to organize the work. Finally, the public opinion pressure is also a factor that affects leadership. Leaders' decisions that fail to meet the expectations of the general public may have a disastrous impact on corporate reputation. Gwyther Matthew (2015) believes that leaders need to avoid problems that lack public trust. This will effectively prevent the company from suffering losses. In fact, the case of Hurricane Gudrum is a typical negative example. After the onset of the hurricane, the public was not informed of the progress of the repair work in real time, and at the same time spent a lot of time on planning instead of 
actions, which caused them to lose the trust from the public and the company's corporate reputation received a huge loss (Erik H Schlie, 2006). As a result, companies need to consider the Leadership Traits of leaders and other factors that affect leadership, such as emotions and ethics, when they resolve crises.

\subsection{Strong Crisis Leadership}

Strong crisis leadership makes everything different, which can be proved by many historical and contemporary examples. There are generally three approaches to crisis resolution: anticipation, prevention, and mitigation. As argued by Caroline (2019), business leaders able to leverage these skills are more likely to achieve long-term success even in the most unfavourable situations.

Anticipation: Although not all crises are foreseeable, some crises are predictable. (Boin, Kuipers \& Overdijk, 2014). Leaders can identify Potential crisis as early as possible by establishing mechanisms to identify the crises (Penrose, 2000). In order to effectively identify potential crises and improve the responsiveness and ability to respond to crises, leaders can establish a policy framework for organizing actions. (Penrose, 2000). The classification of effective crises can help leaders to directly judge potential crises and quickly enter the crisis response stage. There are four criteria for effective crisis classification a) the crisis categories are independent of each other and have clear criteria for differentiation. b) the definition of different types of crises should be comprehensive and detailed, giving leaders a broad and deep understanding of the crisis. Provide more theoretical support for the decision-making of leaders. c) The third crisis classification should help leaders to prevent and understand how to deal with potential crises. d) classification should be practical. The number of types of crisis should be reasonable to facilitate decision-makers (James, Wooten, Pushek, 2011).

The crisis is classified into 16 matrices (Burnet 2016 as cited in Penrose, 2000). The factors influencing these matrices include threat level, degree of control, time pressure, and response options. The level of crisis classification is determined by these four factors. For example, a crisis with a medium threat level, a high degree of control, and small-time pressure are classified as a three-level crisis, which including three influencing factors (Penrose, 2000).Also, the team is critical to a good plan. Team-oriented organizations can better manage crises than organizations that are personally oriented in crisis preparedness. (Pearson et al., 1997). Interpersonal conflicts, ineffective decisions can hinder the effectiveness of crisis management (King, 2002).

Leaders can select and train company spokespersons to identify key audiences and key information by establishing communication protocols. Identify the most appropriate communication method to develop a communication strategy before a crisis occurs (Bernstein, 2004). The communication strategy should explain everything about the crisis (Boin, Kuipers \& Overdijk, 2014). The communication strategy should also include how to identify confidential information and regulate the access rights of on-site media for employees at all levels of the company (Carole,1990). Pre-set crisis communication plan templates, and coordination of procedures with other relevant departments, designate spokespersons and list emergency contacts for the team and other relevant agencies. Should take place (Seeger, 2006). The ability of leaders and their teams to communicate the company's vision has a growing impact on corporate reputation. (Knight, 2017).

Prevention: A crisis may affect not only the internal environment of the company like employees but also the external factors, such as the reputation and stokeholds of an organization (Granville King, III, 2000).Building an effective crisis management mechanism is a requisite plan for any firm to protect an organization and its stakeholders from threats and leaders should perform with sensemaking and perception skills (Walsh, 1995; Weick, 1988). As has been claimed by Dutton \& Jackson (1987) and Wooten \& James (2004). Crisis management, can be divided into five phases (Lynn Perry Wooten Erika Hayes James,2008): - Signal detection phase : includes two-parts; one is sense-making, the leader may need to think the reasons of the event, the means of the event, also the things that should relate to it, meanwhile, the leader should not only sense an individual event but also notice about things that seem unrelated (Weick et al. 2005); also to be explored what kinds of perspectives should the leader take to analyze the crisis. (Brockner and James, 2008). - Prevention/preparation phase: There are three main ideas that should be considered for a crisis. Firstly, is the selling issue, in this stage, executives should engage in the processes and objectives of selling issues as it may influence the set or change the developing direction of a company (Dutton, Ashford, O'Neill, Hayes, \& Wierba, 1997). The second point is the agility of the 
organization, thus, it requires the crisis led to some extent understand all aspects of the organization, Next, we need to admit that the creativity competence of firm that use to predict how a firm will be attacked by which kind of crises may benefit for a firm to contain some activities and control damages as well (Lynn Perry Wooten Erika Hayes James,2008). • Damage control phase: In the third segment of CM is the damage control stage, how to response the event with proper actions under pressure in time is a core competency to the leader. Brockner and James have claimed in 2008, at the beginning of the crises the leader may realize the crisis as a threat rather than think it as a possible opportunity. Besides, the threatening issues always result in negative emotions, such as anxiety (Smith \& Ellsworth, 1985), which will influence the ability of the leader to make a wit decision. Furthermore, the plenty of information of crisis itself also consumes the time of leader, which also increase the difficulty of crisis solving. (Coombs, 1995; James \& Wooten, 2006). • Recovery phase: the need to obtain the trust of stakeholders again is a vital mission for the leader, and the ability to take actions with integrity that consistent with integrity is the basis for rebuilding the trust (James and Wooten, 2006). • Learning and reflection: the crises are more likely to be seen as an opportunity instead of treating it as threats when the decision-makers use previous experience and using a learning orientation and develop new rules to alter the operation of the organization (Brockner \& James, 2008).

Mitigation: Any stakeholder concerns must be heard and addressed immediately and continuously throughout the crisis. A company's reputation determines its market share and is influenced by its shareholders, customers, and other stakeholders (Šontaitė-Petkevičienè, 2014). However, Coombs (2007) claims that no matter what kind of crisis the company is in, the most important thing is to ensure that stakeholders are free of harm, rather than placing the company's reputation in the first place to be protected. A good corporate reputation is a valuable asset for an enterprise, and an asset that other companies cannot replicate (Hoopes, Madsen, \& Walker, 2003). Unlike other valuable resources that are difficult to imitate (human resources and know-how), the competitive advantage that a company's reputation brings to a company is sustainable. Carmeli and Tishler (2004) argue that human capital, management capabilities, and corporate credibility can be of great help to companies' performance and are indispensable. Cravens (2006) also believe that corporate reputation is not generated by regulations but is the result of the joint efforts of corporate leaders and employees. Jackson (2004) believes that reputation is not only brought about by business leaders and corporate employees but includes a large number of members such as consumers, corporate investors, corporate employees, stakeholders, and the general public.

After the crisis, public relations mainly correspond to the 5S principles : • Shoulder the matter: After the crisis occurs, the public will often relate to two issues, the issue of interests and emotional issues. Interests are the focus of public concern. Business leaders need to stand in the position of victims, apologize to the public through the news media, and win public forgiveness. $\bullet$ Sincerity: When the enterprise is in the crisis of public opinion, every move of the enterprise will pay more attention to, enterprise leaders must not have lucky mentality, trying to pass the test. $\bullet$ Speed: At that time, the spread of social information was extremely fast. After the crisis, various rumors could easily flood the Internet. Business leaders must react quickly and communicate with the media to prevent the situation from escalating and expanding. System: After the crisis, corporate leaders must remain calm and reduce the psychological pressure on employees, and at the same time, the corporate leadership must develop a unified solution. After the plan is formulated, a public relations team should be established immediately to implement the plan quickly. At the same time, the public relations team must have efficient execution to ensure that the crisis can be completely resolved. - Standards: After the crisis, companies often lack the credibility to justify themselves. Business leaders need to invite influential people or organizations to justify themselves, eliminate public relations suspicions, and regain public trust. As Fombrun (1996) and Bromley (2002) have found that corporate credibility is a collective assessment of a company's past behaviour and outcomes, not only that, corporate credibility also represents other value outcomes that are provided to various stakeholder groups ability. Crisis is inevitable in the life cycle of any organization. In a crisis, only active monitoring and listening, and strategically balancing communication with traditional and social media are the right approach. 


\section{Conclusion}

Crises often become inevitable situations for any individual company, regardless of its size and its reputation. To ensure resilience to crisis, leaders are required to create a culture \& develop mechanism that can facilitate the prediction of threats and risks, assist quick and effective responsiveness in an honest way when threats appear. This assists companies to minimize the extent of loses during \& after a crisis and above all to prevent the occurrence of a reputational damage. The requirements for a results-oriented leadership are especially demanding in a crisis and post crisis period of time. Though companies are incapable of comprehensive preparation for crises, they can put in place various scientific management processes, to incorporate crisis management practices into operations and to integrate potential risks and vulnerability assessments into the process of strategic debate and planning. The restoration of corporate reputation is among the most significant issues that has to be prioritized by corporate leaders but also to be acknowledged the possible opportunities that may arise. In his way, the post-crisis recovery may be considered as an opportunity for changes \& improvements and once again the role of corporate leaders is important. Therefore, effective leadership can end up turning a crisis into another opportunity.

\subsection{Limitations}

There are some limitations regarding the present study; specifically, here mainly literature review is applied as main methodological approach whereas an empirical study through distribution of questionnaires in organizations experiencing stressful situations and risk of damage of corporate reputation could add value or/and enhance our findings. Also, the perspective of the research context could be enhanced examining the influence of specific factors such as corporate culture, organizational climate, market characteristics and other on leadership approach dealing with a crisis as well as how corporate reputation may also influence leadership style in a stressful situation.

\section{References}

Adeosun, L. P. K., \& Ganiyu, R. A. (2013). Corporate reputation as a strategic asset. International Journal of Business and Social Sciences, 4(2), 220.

Aviation P. (2005). Fuel Costs in Katrina's Aftermath Will Affect Airlines. Retrieved December 2, 2019, from https://www.aviationpros.com/home/news/10432407/fuel-costs-in-katrinas-aftermath-will-affect-airlines

Barton, L. (1993). Crisis in organizations: Managing and communicating in the heat of chaos. Cincinnati, OH: SouthWestern Publishing Company.

Benoit, W. L. (1995). Accounts, Excuses, and Apologies (State University of New York Press, Albany, NY).

Benson, J. A. (1988). Crisis revisited: An analysis of strategies used by Tylenol in the second tampering episode. Communication Studies, 39(1), 49-66.

Bernstein, J. (2004). The 10 steps of crisis communications. Crisis Response, prevention, Planning and, Training, 106, 1020.

Boin, A. (2005). Disaster research and future crises: Broadening the research agenda. International Journal of Mass Emergencies and Disasters, 23(3), 199.

Boin, A., \& Hart, P. 't (2003). Public Leadership in Times of Crisis: Mission Impossible? Public Administration Review, 63(5), 544-553.

Boin, A., Kuipers, S., \& Overdijk, W. (2013). Leadership in times of crisis: A framework for assessment. International Review of Public Administration, 18(1), 79-91.

Bowers, M., Hall, J., \& Srinivasan, M. (2017). Organizational culture and leadership style: The missing combination for selecting the right leader for effective crisis management. Business Horizons, 60(4),551-563.

Brockner, J. B., \& James, E. H. (2008). Toward an understanding of when executives see opportunity in crisis. Journal of Applied Behavioral Sciences, 44(7), 94-115.

Bromley, D. (2002). Comparing corporate reputations: League tables, quotients, benchmarks, or case studies? Corporate Reputation Review, 5(1), 35-50.

Bruce, A. J., \& Luthans, F. (2009). The High Impact Leader: moments matter in accelerating, authentic leadership development (Skimming and Scanning).

Brumfield, K. (2012). Succeeding in crisis leadership. Financial Executive, October 2012.

Burgess, K. A., Riddle, D. L., Hall, J. K., \& Salas, E. (1992). March. Principles of team leadership under stress. In 38th annual meeting of the South-eastern Psychological Association, Knoxville, TN.

Burke, S. E. (2003). Reputation Marketing: Building and Sustaining Your Organization's Greatest Asset. Journal of Consumer Marketing, 1(1), 1-10.

Carmeli, A., \& Tishler, A. (2004). The relationships between intangible organizational elements and organizational performance. Strategic Management Journal, 25(13), 1257-1278. 
Carole, G. (1990). Crisis Management: How to Plan Ahead for Potential Crises. American School \& University, 62, 20a22a.

Carroll, A. B. (2015). Corporate social responsibility. Organizational Dynamics, 44(2), 87-96.

Chun, R., Da Silva, R., Davies, G., \& Roper, S. (2005). Corporate reputation and competitiveness. Routledge, UK

Cleland, D.I. (1995). Leadership and the project-management body of knowledge. International Journal of Project Management, 13(2), 83-88.

Collins, M., \& Jackson, C. (2015). A process model of self-regulation and leadership: How attentional resource capacity and negative emotions influence constructive and destructive leadership. The Leadership Quarterly, 26(3), 386-401.

Comfort, L. K. (2007). Crisis management in hindsight: Cognition, communication, coordination, and control. Public Administration Review, 67, 189-197.

Comyns, B., \& Franklin-Johnson, E. (2016). Corporate Reputation and Collective Crises: A Theoretical Development Using the Case of Rana Plaza. Journal of Business Ethics, 150(1), 159-183.

Contini, M., Annunziata, E., Rizzi, F., \& Frey, M. (2019). Exploring the influence of Corporate Social Responsibility (CSR) domains on consumers' loyalty: an experiment in BRICS countries. Journal of Cleaner Production, 119-158.

Coombs, W. T. (1995). Choosing the right words: The development of guidelines for the selection of the "appropriate" crisis response strategies. Management Communication Quarterly, 8, 447-476.

Coombs, W. T. (2007). Protecting organization reputations during a crisis: The development and application of situational crisis communication theory. Corporate Reputation Review, 10(3), 163-176.

Coombs, W.T. (2006). The Protective Powers of Crisis Response Strategies. Journal of Promotion Management, 12(3-4), $241-260$.

Coombs, W.T. \& Laufer, D. (2018). Global Crisis Management - Current Research and Future Directions. Journal of International Management, 24(3), 199-203.

Cravens, K. S., \& Oliver, E. G. (2006). Employees: The key link to corporate reputation management. Business Horizons, 49(4), 293-302.

Cron, W., Slocum, J., VandeWalle, D., \& Fu, F. (2005). The role of goal orientation on negative emotions and goal setting when initial performance falls short of one's performance goal. Human Performance, 18(1), 55-80.

Davies, G., \& Chun, R. (2009). The leader's role in managing reputation. https://doi.org/10.1007/978-3-642-01630$1 \_21$

Dean, D. H. (2004). Consumer reaction to negative publicity: Effects of corporate reputation, response, and responsibility for a crisis event. The Journal of Business Communication (1973), 41(2), 192-211.

Dhanesh, G. S., \& Sriramesh, K. (2018). Culture and Crisis Communication: Nestle India's Maggi Noodles Case. Journal of International Management, 24(3), 204-214.

Dowling, R. (1993). Developing your company image into a corporate asset. Long Range Planning, 26(2),101-109.

Du, S., Bhattacharya, C. B., \& Sen, S. (2007). Reaping relational rewards from corporate social responsibility: The role of competitive positioning. International Journal of Research in Marketing, 24(3), 224-241. Retrieved Aug. 13, 2019, from https://www.sciencedirect.com/science/article/abs/pii/S0167811607000286

Dumortier, F. (2010). Facebook and Risks of "De-contextualization" of Information. Data Protection in a Profiled World, 119-137. Retrieved Nov. 30, 2019, https://link.springer.com/chapter/10.1007/978-90-481-8865-9_7

Dutton, J. E., \& Jackson, S. E. (1987). Categorizing strategic issues: Links to organi- zational action. The Academy of Management Review, 12(1), 76-90.

Dutton, J. E., Ashford, S. E., O'Neill, R., Hayes, E., \& Wierba, E. (1997). Reading the wind: How to assess the context for issue-selling. Strategic Management Journal, 18(5), 407-525.

Dzhereliuk I. O. (2018). Analyzing the Components of Providing Both External and Internal Anti-Crisis Stability of Tourism Enterprises. Business Inform, 3(482), 364-370.

Fearn-Banks, K. (1996). Crisis Communication: A Casebook Approach (Lawrence Erlbaum Associates Publishers, Mahwah, NJ).

Fombrun, C. (1996). Reputation: Realizing value from the corporate image. Boston : Harvard Business School Press. Coûts d'opportunité liés d la maximisation de la performance en marketing (Olivier Furrer et D), Su clharshan.

Gillentine, A. (2006). Timberland to provide "nutritional label" for all shoes. The Colorado Springs Business Journal, 1, 1034748-1.

Gooty, J., Connelly, S., Griffith, J., \& Gupta, A. (2010). Leadership affect and emotions: A state of the science review. The Leadership Quarterly, 21(6), 979-1004.

Granville K. III, (2002). Crisis Management \& Team Effectiveness: A Closer Examination. Journal of Business Ethics, 41, 235-249.

Groves, K. S., \& LaRocca, M. A. (2011). An Empirical Study of Leader Ethical Values, Transformational and Transactional Leadership, and Follower Attitudes Toward Corporate Social Responsibility. Journal of Business Ethics, 103(4), 511-528. 
Gwyther, M. (2015). Leadership in crisis. London Business School Review, 26(4), 40-43. Retrieved Nov. 26, 2019, from https://onlinelibrary.wiley.com/doi/10.1111/2057-1615.12076

Hall, N., Lacey, J., Carr-Cornish, S., \& Dowd, A. M. (2015). Social licence to operate understanding how a concept has been translated into practice in energy industries. Journal of Cleaner Production, 86, 301-310.

Halverson, S. K., Murphy, S. E., \& Riggio, R. E. (2004). Charismatic Leadership in Crisis Situations. Small Group Research, 35(5), 495-514.

Helm, S. (2007). One reputation or many? Corporate Communications: An International Journal, 12(3), 238-254.

Helm, S., \& Tolsdorf, J. (2013). How Does Corporate Reputation Affect Customer Loyalty in a Corporate Crisis? Journal of Contingencies and Crisis Management, 21(3), 144-152.

Hoffmann, K. (2007). Handling Reputation Crises: How three organisations managed to restore their undeservedly damaged reputations.

Hoopes, D. G., Madsen, T. L., \& Walker, G. (2003). 'Why is there a resource-based view? Toward a theory of competitive heterogeneity. Strategic Management Journal, 24(10), 889-902.

Hsu, K. T. (2012). The Advertising Effects of Corporate Social Responsibility on Corporate Reputation and Brand Equity: Evidence from the Life Insurance Industry in Taiwan. Journal of Business Ethics, 109(2), 189-201.

Ip, C. Y., Liang, C., \& Feng, J. Y. (2018). Determinants of public attitude towards a social enterprise crisis in the digital era: Lessons learnt from THINX. Public Relations Review, 44(5), 784-793.

Jackson, K. T. (2004). Building reputational capital: Strategies for integrity and fair play that improve the bottom line. Oxford University Press.

James, E. H., \& Wooten, L. P. (2006). Diversity crises: How firms manage discrimina- tion lawsuits. Academy of Management Journal, 49(6), 1103-1118.

Jaques, T. (2012). Crisis leadership: a view from the executive suite, Journal of Public Affairs, 12(4), 366-372.

Jordan-Meier, J. (2012). Appearances do matter: Leadership in a crisis. Leader to Leader, 2012(66), 16-20.

Knight, C. (2017). The Importance of Leadership in Managing Reputation.

https://www.reputationinstitute.com/sites/default/files/pdfs/Importance-Leadership-Managing-Reputation

Krasikova, D., Green, S., \& Lebreton, J. (2013). Destructive Leadership: A Theoretical Review, Integration, and Future Research Agenda. Journal of Management, 39(5), 1308-1338.

Kruse, K. (2015). What Is Leadership? Forbes. Nov. 26, 2019, from https:/ /www.forbes.com/sites/kevinkruse/

Leven, B. (2011). Avoiding crisis contagion: Poland's case. Communist \& Post-Communist Studies,44(3),183-187.

Li, Z., \& Wang, H. (2009). Research on the Enterprise Crisis Management System Basic on Knowledge Demand. Retrieved Nov. 30, 2019, from https:// pdfs.semanticscholar.org/648d/e6a8fd207226dac3635c2ea 50dd7469

Links, K.V., Servaes, H., \& Tamayo, A. (2017). Social Capital, Trust, and Firm Performance: The Value of Corporate Social Responsibility during the Financial Crisis. The Journal of Finance, 72(4), 1785-1824.

Lynn, P., Wooten, E., \& Hayes, J. (2008). Linking Crisis Management and Leadership Competencies: The Role of Human Resource Development. Advances in Developing Human Resources, 10(3), 352-379.

Madera, J. M., \& Smith, D. B. (2009). The effects of leader negative emotions on evaluations of leadership in a crisis situation: The role of anger and sadness. The Leadership Quarterly, 20(2), 103-114.

Mahon, J. F. (2002). Corporate reputation: Research agenda using strategy and stakeholder literature. Business $\mathcal{E}$ Society, 41(4), 415-445.

Maldonado, T., \& Vera, D. (2014). Leadership skills for international crises: The role of cultural intelligence and improvisation. Organizational Dynamics, 43(4), 257-265.

Martin, G., \& Hetrick, S. (2006). Corporate reputations, branding, and people management: A strategic approach to HR. Routledge.

Mayer, D., Kuenzi, M., \& Greenbaum, M. (2010). Examining the Link Between Ethical Leadership and Employee Misconduct: The Mediating Role of Ethical Climate. Journal of Business Ethics, 95(S1), 7-16.

Meriwether, G. (2018). Leadership in crisis. The Leadership Challenge, USA: Jossey-Bass Publications.

Messick, D.M. \& Bazerman, M. (1996). Ethical Leadership and the Psychology of Decision Making. [online] MIT Sloan Management Review. Retrieved Nov. 21, 2019, https://sloanreview.mit.edu/article/ethical-leadership

Monden, \& Monden, Yasuhiro. (2014). Management of Enterprise Crises in Japan.

Neville, B. A., Bell, S. J., \& Mengüç, B. (2005). Corporate reputation, stakeholders, and the social performance-financial performance relationship. European Journal of Marketing, 39(9/10), 1184-1198.

Yu., O.G.O., \& Derevyanko. (2015). Essence, classification, and reason of crisis appearance in the enterprises' activity. Vìsnik Žitomirs'kogo Deržavnogo Tehnologìčnogo Unìversitetu. Ekonomičnì Nauki, 1(71), 80-88.

Obydiennova Tetiana, et al. (2019). Impact of Resource Provision of Enterprises on Anti-Crisis Measures. Modern Economics, 14, 200-205.

Patrick, L., Adeosun, K., \& Ganiyu, R. (2013). Corporate Reputation as a Strategic Asset. International Journal of Business and Social Science, 4(2), 220.

Pearson, C. M., \& Clair, J. A. (1998). Reframing crisis management. Academy of management review, 23(1), 59-76. 
Rajah, R., Song, Z., \& Arvey, R. (2011). Emotionality and leadership: Taking stock of the past decade of research. The Leadership Quarterly, 22(6), 1107-1119.

Repec.org. (2019). EconPapers: Journal of Business Ethics. https://econpapers.repec.org/article/kapjbuset/default

Ritchie W., \& Jiang Y, (2019). A Review of Research on Tourism Risk, Crisis and Disaster Management: Launching the Annals of Tourism Research Curated Collection on Tourism Risk, Crisis and Disaster Management. Annals of Tourism Research, 79, 1-10.

Roberts, P. W., \& Dowling, G. R. (2002). Corporate reputation and sustained superior financial performance. Strategic Management Journal, 23(12), 1077-1093.

Schnietz, K. E., \& Epstein, M. J. (2005). Exploring the Financial Value of a Reputation for Corporate Social Responsibility During a Crisis. Corporate Reputation Review, 7(4), 327-345.

Schoenberg A. (2005). Does crisis plan matter? A new perspective on leading during a crisis. Public Relations Quarterly, $50(1), 2-6$.

Siano, A., Vollero, A., Conte, F., \& Amabile, S. (2017). "More than words": Expanding the taxonomy of greenwashing after the Volkswagen scandal. Journal of Business Research, 71, 27-37.

Smith, C., \& Ellsworth, P. (1985). Patterns of cognitive appraisals in emotions. Journal of Personality and Social Psychology, 48, 813-838.

Šontaitè-Petkevičienė, M. (2014). Crisis management to avoid damage for corporate reputation: the case of retail chain crisis in the Baltic countries. Procedia-Social and Behavioral Sciences, 156, 452-457.

Spreier, S., Fontaine, M. \& Malloy, R. (2006). Leadership run amok. The destructive potential of overachievers. Harvard Business Review, 84(6), 72-82.

Sy, T., Côté, S. \& Saavedra, R. (2005). The Contagious Leader: Impact of the Leader's Mood on the Mood of Group Members, Group Affective Tone and Group Processes. Journal of Applied Psychology, 90(2), 295-305.

Tokakis, V., Polychroniou, P., \& Boustras, G. (2019). Crisis management in public administration: The three phases model for safety incidents. Safety Science, 113, 37-43. Retrieved from https:/ / www.sciencedirect.com/science

Tom, L. (2018). Incorporating Social Activism. Retrieved Nov. 27, 2019, from https://papers.ssrn.com/sol3/papers.cfm?abstract_id=3294317

Toor, S., \& Ofori, G. (2009). Ethical Leadership: Examining the Relationships with Full Range Leadership Model, Employee Outcomes, and Organizational Culture. Journal of Business Ethics, 90(4), 533-547.

Trainor, J. E., \& Velotti, L. (2013). Leadership in Crises, Disasters, and Catastrophes. Journal of Leadership Studies, 7(3), 38-40.

Ulmer, R. R., \& Sellnow, T. L. (2000). Consistent questions of ambiguity in organizational crisis communication: Jack in the Box as a case study. Journal of Business Ethics, 25(2), pp.143-155.

Us, Y. V., \& Kuznetsova, G. V. (2018). Dialectic Approach to Forming the Theoretical Bases of Strategic Controlling in the System of Enterprise Crisis Management. The Problems of Economy, 4(38), 155-161.

Vidaver-Cohen, D. (2004). Management, meaning and a meeting of the minds: How symbolic power preserves reputation in times of corporate crisis. 8th International Conference on Corporate Reputation, Image, Identity and Competitiveness. Fort Lauderdale, Florida.

Walsh, G., Schaarschmidt, M., \& Von Kortzfleisch, H. (2016). Employees' company reputation-related social media competence: Scale development and validation. Journal of Interactive Marketing, 36, 46-59.

Weick, K. (1988). Enacted sense-making in crisis situations. Journal of Management Studies, 25(4), 306-317.

Weick, K. E., Sutcliffe, K. M., \& Obstfeld, D. (2005). Organizing and the process of sense making. Organization Science, 14(4), 409-421.

Wingfield, N. \& Stelter, B. (2011). How Netflix Lost 800,000 Members, and Good Will. Retrieved Nov. 29, 2019, from http:/ / faculty.ses.wsu.edu/rayb/econ301/Articles/Netflix\%20Lost\%20800\%2C000\%20Members\%20.

Wofford, J.C. \& Goodwin, V.L. (1994). A cognitive interpretation of transactional and transformational leadership theories. The Leadership Quarterly, 5(2), pp.161-186.

Worldcat.org. (2014). Management of enterprise crises in Japan (eBook, 2014) [WorldCat.org]. Retrieved Nov. 30, 2019, from https://www.worldcat.org/title/management-of-enterprise-crises-in-japan/oclc/860388717

Xu, Q., Zhu, L., Zheng, G., \& Wang, F. (2007). Haier's Tao of innovation: a case study of the emerging Total Innovation Management model. The Journal of Technology Transfer, 32(1-2), 27-47.

Yongling, D. (2011). Research on Public Relations Strategies in Enterprise Crisis. Energy Procedia, 13,2463-2469.

Young, C.L. \& Flowers, A. (2012). Fight Viral with Viral: A Case Study of Domino's Pizza's Crisis Communication Strategies. Retrieved Nov. 29, 2019, from http://cssc.uscannenberg.org/wp-content/uploads/2013/10/v1art6

Yukl, G. (1999). An evaluation of conceptual weaknesses in transformational and charismatic leadership theories. The Leadership Quarterly, 10(2), 285-305.

Yukl, G. (2006). Leadership in organizations. 6th ed. Upper Saddle River, N.J.: Pearson Prentice Hall.

Zheng-chu, H. E. (2003). A Study on the Construction of Enterprise Crisis Management System [J]. Systems Engineering, 3. 
Zhu, W., Avolio, B., Riggio, R., \& Sosik, J. (2011). The effect of authentic transformational leadership on follower and group ethics. The Leadership Quarterly, 22(5), 801-817.

Zhu, Z., Hoffmire, J., Hoffmire, J., \& Wang, F. (2013). Employee Stock Ownership Plans and Their Effect on Productivity: The Case of Huawei. International Journal of Business and Management Invention, 2, 17-22. 